\title{
Effect of polydimethylsiloxane incorporation on the properties of polyimides synthesized from newly designed $\alpha, \alpha^{\prime}$-bis(2-aminophenoxy)-p-xylene
}

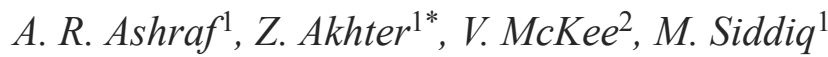 \\ ${ }^{1}$ Department of Chemistry, Quaid-i-Azam University, 45320 Islamabad, Pakistan \\ ${ }^{2}$ School of Chemical Sciences, Dublin City University, Glasnevin, Dublin 9, Ireland
}

Received 7 April 2015; accepted in revised form 26 June 2015

\begin{abstract}
A novel diamine monomer $\alpha, \alpha^{\prime}$-bis(2-aminophenoxy)-p-xylene (2APX) was synthesized and condensed with four different dianhydrides to prepare a series of polyimides. Aminopropyl terminated polydimethylsiloxane (PDMS) was incorporated within the backbone of polyimides for the preparation of poly(imide siloxane) copolymers. Fourier transform infrared (FTIR), ${ }^{1} \mathrm{H}$ and ${ }^{13} \mathrm{C}$ nuclear magnetic resonance (NMR) spectroscopic studies accompanied by elemental and single crystal X-ray analysis were performed for structure elucidation of 2NPX and 2APX. The crystal system of the 2NPX was found to be monoclinic, belonging to space group $P 2_{1} / \mathrm{n}$ while $2 \mathrm{APX}$ was triclinic with space group $P \overline{\mathrm{l}}$. The structural elucidation of polymers was carried out by FTIR and ${ }^{1} \mathrm{H}$ NMR spectroscopy and their properties were studied by solubility testing, wide angle X-ray diffraction (WAXRD), thermogravimetric analysis (TGA) and viscosity measurement along with laser light scattering technique (LLS). WAXRD pattern showed the semicrystalline nature of polyimides which was decreased in case of copolymers. The poly(imide siloxane) copolymers displayed slightly lower temperature resistance but improved solubility as compared to polyimides. Maximum degradation temperature $\left(T_{\max }\right)$ of polyimides was in the range of $523-570^{\circ} \mathrm{C}$ while that of copolyimides, ranged between $483-525^{\circ} \mathrm{C}$. Similarly, a decline in inherent viscosities and increase in molecular weight was noticed while moving from polyimides to copolyimides.
\end{abstract}

Keywords: polymer synthesis, molecular engineering, 2APX, single crystal, poly(imide siloxane) copolymers, laser light scattering

\section{Introduction}

The advances in the field of high performance materials demand a unique combination of properties i.e. good oxidative and thermal stability, high glass transition temperature, excellent mechanical properties, good adhesion along with chemical, wear, fire and radiation resistance for diverse range of applications including aerospace, automotive and microelectronic industries, as films, adhesives, sealants, coatings, insulators, gas separation membranes etc. In this regard, large number of polymeric materials such as polyamides, polyimides, poly(amide-imide)s polybenzimidazoles, polyethers, polyketones, polysulphones, and polyesters have been developed in order to replace metal, ceramic or glass and reduce the cost of present day industrial processes [1-7]. Polyimides especially aromatic polyimides have attracted the attention of scientists and engineers more than any other polymer as they have great potential to serve this purpose due to favorable combination of aforementioned sought properties [8]. At present time, polyimides are considered as versatile polymers with an almost unlimited spectrum of applications in advanced technologies. The

\footnotetext{
*Corresponding author, e-mail: zareenakhter@yahoo.com (C) BME-PT
} 
exceptional properties displayed by the polyimides are reliant on their chemical structure, composition, molecular aggregation and intra or interchain molecular interactions, hence can be tailored to desired ones through changing the chemical structure and molecular composition of polyimides. In this respect, various strategies can be applied i.e. modification of monomers in order to endow the polymer chain with new functionalities, composite engineering or copolymerization etc. Therefore, the curiosity of academic and industrial research is the production of new polyimide based materials so as to further enhance their properties and diversify applications. Much research has been carried out in last few years to improve certain properties of polyimides for specific applications. For instance, main disadvantage associated with the application of polyimide films in optoelectronic industry is their yellowish nature. This is attributed to the intra or intermolecular charge transfer complex (CTC) formation between the alternating electron-acceptor dianhydride and electron-donor diamine moieties in the polymer chain [9]. It was prophesied that use of weak electron-accepting dianhydrides or electrondonating diamines will suppress these charge transfer (CT) interactions. Keeping this in mind Haixia Yang and coworkers prepared fluorinated polyimides from diamines bearing electron withdrawing trifluoromethyl substituents (lowering its electron-donating ability) and observed significantly enhanced optical transparency [10]. Semi-aromatic polyimides derived from alicyclic dianhydride i.e. 1,2,4,5cyclohexanetetracarboxylic dianhydride (weak electron-accepting) and different aromatic diamines also produced alike results [11]. Likewise, introduction of flexible spacers $\left(-\mathrm{O}-,-\mathrm{CO}-,-\mathrm{SO}_{2}-\right)$ [12], kink in structure through ortho or meta catenation instead of para [13], bulky pendant groups or hinge atoms [14] or trifluoromethyl groups $\left(-\mathrm{CF}_{3}\right)$ [15] in the structure of either diamine or dianhydride led to improvement in processability and solubility of polyimides while upholding their beneficial properties. Polyimides with significantly enhanced thermal and mechanical properties were produced by the incorporation of heterocyclic rings of benzimidazole, benzoxazole, pyrimidine and benzoxadiazole into the backbone of polyimides [16]. Juntao $\mathrm{Wu}$ studied the influence of nano-sized $\mathrm{Al}_{2} \mathrm{O}_{3}$ content on various properties of $\mathrm{PI} / \mathrm{Al}_{2} \mathrm{O}_{3}$ nanocomposites and found that the incorporation of $\mathrm{Al}_{2} \mathrm{O}_{3}$ in the polyimide triggered an increase in thermal stability, Young's modulus and electrical aging performance of hybrid films as compared to pure polyimide [17]. Copolymerization strategy i.e. synthesis of polymers from two different diamines or dianhydrides is also applied to modify the properties of polyimides [18-20]. In this regard, aminopropyl terminated polydimethylsiloxane (PDMS) is often covalently incorporated within the polyimide chain. Polydimethylsiloxane is a flexible inorganic elastomer having very low glass transition temperature $\left(-123^{\circ} \mathrm{C}\right)$ and imparts several beneficial properties to the polymeric system into which it is co-reacted e.g. improved solubility and flame resistance, increased permeability, permselectivity, adhesive ability and impact resistance, reduced water absorption and dielectric constant, modified surface properties, superior electrical properties etc. [21-27]. Therefore, silicone containing polyimides have attracted significant attention recently and studies are mainly focused on investigating the effects of polydimetylsiloxane incorporation on the aforementioned properties of polyimides. In this context, Othman reported a series of poly(siloxane-imide) block copolymers and concluded that incorporation of silicon units into the polyimide chains significantly reduced the refractive index and dielectric constant with reasonably low dielectric loss [28]. Similarly, Ku and coworkers observed that pyridine-containing poly(imidesiloxane)s showed stronger adhesion to copper foils along with lower moisture absorption as compared to conventional aromatic polyimides [29].

While improving a particular property of polyimide, it has to be remembered that their thermal and mechanical properties for which these are known for, must not be compromised. Therefore, an adjusted degree of structural modification should be applied so as to optimize the balance of properties.

This article reports the synthesis of polyimides and siloxane-containing copolyimides derived from a newly designed ether based diamine monomer i.e. $\alpha, \alpha^{\prime}$-bis(2-aminophenoxy)-p-xylene. This new diamine was characterized by FTIR and NMR spectroscopic techniques along with elemental and single crystal X-ray diffraction analysis. FTIR and NMR spectroscopy, solubility, WAXRD, thermal, viscometric and laser light scattering analysis were carried out for the synthesized polymers and copolymers. The emphasis of the study was to evaluate the properties of polyimides derived from diamine hav- 
ing amino group at ortho position with respect to ether linkage and monitor the influence of polydimethylsiloxane incorporation on solubility, crystallinity, thermal stability, viscosity, and molecular weight of parent polyimides.

\section{Experimental}

\subsection{Materials}

All chemicals and reagents used for the synthesis of diamine, polyimides and poly(imide siloxane) copolymers were of highest purity and were used as received. 2-nitrophenol (2NP), potassium carbonate anhydrous $\left(\mathrm{K}_{2} \mathrm{CO}_{3}\right)$, pyromellitic dianhydride (PMDA), 3,3',4,4'-benzophenonetetracarboxylic dianhydride (BTDA) and oxydiphthalic anhydride (ODPA) were purchased from Fluka Chemie $\mathrm{GmbH}$ (Buchs, Switzerland). While 2,2-bis(3,4-dicarboxyphenyl)hexafluoropropane dianhydride (6FDA), 1,4-bis(chloromethyl) benzene (CMB), 5\% palladium on activated carbon $(\mathrm{Pd} / \mathrm{C})$ and aminopropyl terminated polydimethylsiloxane (PDMS) of $M_{\mathrm{n}}=$ 2500 were obtained from Sigma Aldrich Chemie GmbH (Schnelldorf, Germany). Hydrazine monohydrate was procured from Merck (Darmstadt, Germany). Solvents, N-methylpyrrolidone (NMP), N,Ndimethylacetamide (DMAc), N,N-dimethylformamide (DMF), tetrahydrofuran (THF) ethanol, were acquired from various commercial sources and were dried before use [30].

\subsection{Instrumentation and measurements}

Melting temperatures of the aromatic dinitro and diamine compounds were determined in a capillary tube using Gallenkamp electrothermal melting point apparatus (Staffordshire, UK). The solid state Fourier transform infrared (FTIR) spectra (400$4000 \mathrm{~cm}^{-1}$ ) were obtained using Thermo Nicolet6700 spectrophotometer (Madison, USA). Nuclear magnetic resonance (NMR) spectra were recorded in deuterated DMSO- $d_{6}$ using Bruker spectrometer (Bruker NMR Instruments) operating at $300 \mathrm{MHz}$ for ${ }^{1} \mathrm{H}$ NMR and at $75 \mathrm{MHz}$ for ${ }^{13} \mathrm{C}$ NMR using tetramethylsilane (TMS) as internal reference. The elemental analyses were performed using CHNS932 LECO instrument (Michigan, USA). Single crystal X-ray data of $\alpha, \alpha^{\prime}$-bis(2-nitrophenoxy)-pxylene and $\alpha, \alpha^{\prime}$-bis(2-aminophenoxy)-p-xylene were obtained on a Bruker Apex II CCD diffractometer (Bruker XRD Instruments) at $150 \mathrm{~K}$. Wideangle X-ray diffractograms were obtained using PANalytical PW 3040/60 X'Pert PRO diffractometer (Almelo, Netherlands). Thermogravimetric analysis (TGA) were carried out using Perkin-Elmer Pyris instrument (Waltham, USA) at a heating rate of $20^{\circ} \mathrm{C} / \mathrm{min}$ in a nitrogen atmosphere up to a maximum temperature of $800^{\circ} \mathrm{C}$. The inherent viscosities of the polyimides were determined using Ubbelohde's viscometer at $25^{\circ} \mathrm{C}$ by dissolving $0.2 \mathrm{~g} / \mathrm{dL}$ of sample in DMSO. Molecular weights and radius of gyration $\left(R_{\mathrm{g}}\right)$ of polymers were determined by dissolving $0.8 \mathrm{~g} / \mathrm{dL}$ of sample in DMSO through static laser light scattering technique using Brookhaven's BI-200 SM instrument (Holtsville NY, USA) fitted with Argon-Ion laser (Coherent Innova) with vertically polarized incident light of wavelength $637 \mathrm{~nm}$ and a BI 900 At digital correlator.

\subsection{Monomer synthesis}

\subsubsection{Synthesis of}

$\alpha, \alpha^{\prime}$-bis(2-nitrophenoxy)-p-xylene (2NPX)

2NPX was synthesized by the Williamson's etherification reaction of 2-nitrophenol with 1,4-bis(chloromethyl)benzene according to Figure 1. For this purpose, a $250 \mathrm{~mL}$ two neck round-bottom flask fitted with reflux condenser and nitrogen tube was charged with $11.12 \mathrm{~g}$ of 2-nitrophenol ( $80 \mathrm{mmol}), 7.00 \mathrm{~g}$ of 1,4-bis(chloromethyl)benzene (40 mmol), $11.00 \mathrm{~g}$ of potassium carbonate (anhydrous) and $60 \mathrm{~mL}$ of

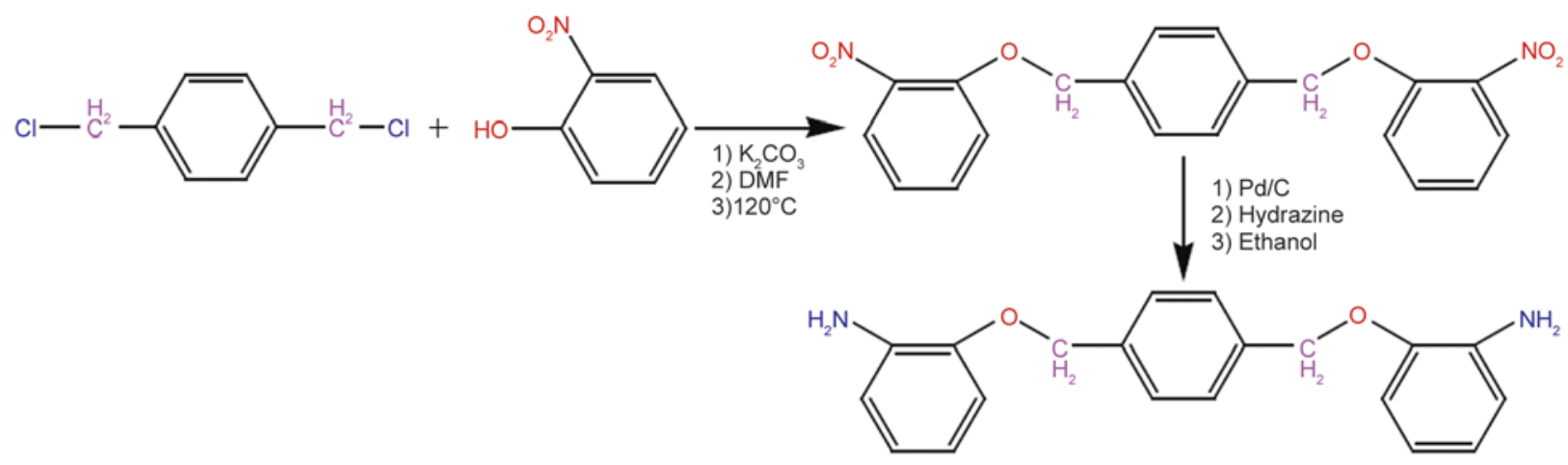

Figure 1. Scheme for synthesis of 2APX 
DMF. The resulting mixture was heated at $120^{\circ} \mathrm{C}$ for $16 \mathrm{hrs}$. The color of solution was changed from yellow to dark brown. It was then cooled to room temperature and poured into $800 \mathrm{~mL}$ of ice cold water. Light yellow precipitates were formed which were filtered, washed with ethanol and dried. The yield of reaction was found to be $78 \%$ and melting point of the product determined was $165^{\circ} \mathrm{C}$.

\subsubsection{Synthesis of}

$\alpha, \alpha^{\prime}$-bis(2-aminophenoxy)-p-xylene (2APX)

For the synthesis of 2APX, $3.0 \mathrm{~g}$ of the obtained dinitro compound (2NPX) $(7.89 \mathrm{mmol}), 0.10 \mathrm{~g}$ of $5 \% \mathrm{Pd} / \mathrm{C}$ and $50 \mathrm{~mL}$ ethanol were introduced in a two neck round-bottom flask, to which $10 \mathrm{~mL}$ of hydrazine monohydrate was added dropwise. After the addition was complete, the reaction was continued at reflux temperature for $12 \mathrm{hrs}$. Then the mixture was filtered in hot form to remove $\mathrm{Pd} / \mathrm{C}$ and solvent was rotary evaporated to get the solid product. The crude product was washed with water to remove any trapped hydrazine and finally recrystallized from ethanol. White colored diamine was obtained in $69 \%$ yield having melting point at $124^{\circ} \mathrm{C}$.

\subsection{Synthesis of polyimides}

Polyimides were synthesized from diamine 2APX and dianhydrides via a two-step route as shown in Figure 2a. The synthesis of polyimide PMDA-2APX is used as an example to illustrate the general synthetic procedure: a $50 \mathrm{~mL}$ two neck round-bottom flask (prebaked on vacuum to exclude any moisture) was charged with $0.320 \mathrm{~g}$ of $2 \mathrm{APX}(1 \mathrm{mmol})$ and $4 \mathrm{~mL}$ DMF. After the complete dissolution of diamine, $0.218 \mathrm{~g}$ of PMDA ( $1 \mathrm{mmol}$ ) was added to this solution by dissolving it in $4 \mathrm{~mL}$ DMF. The mixture was allowed to stir at room temperature under the inert atmosphere of nitrogen for $24 \mathrm{hrs}$. The resulting poly(amic acid) solution was thermally imidized by casting it on a clean glass plate followed by curing with a programmed procedure in a vacuum oven: $18 \mathrm{hrs}$. at $80^{\circ} \mathrm{C}, 1 \mathrm{hr}$ at $150^{\circ} \mathrm{C}, 1 \mathrm{hr}$ at $200^{\circ} \mathrm{C}, 1 \mathrm{hr}$ at $250^{\circ} \mathrm{C}$ and $2 \mathrm{hrs}$ at $300^{\circ} \mathrm{C}$ to produce a fully imidized polyimide. Similarly, 2APX was condensed with 3,3',4,4'-benzophenone tetracarboxylic dianhydride (BTDA), oxydiphthalic anhydride (ODPA) and 2,2-bis(3,4-dicarboxyphenyl) hexafluoropropane dianhydride (6FDA) for the preparation of BTDA-2APX, ODPA-2APX and 6FDA-2APX polyimides.

\subsection{Synthesis of poly(imide siloxane) copolymers}

The poly(imide siloxane) copolymers were synthesized by one-step condensation polymerization reactions of equimolar amounts of diamine 2APX and different dianhydrides in the presence of aminopropyl terminated polydimethyl siloxane (PDMS). The synthesis of PMDA-2APX-PDMS is presented as an example to describe the synthetic procedure: a $50 \mathrm{~mL}$ two neck round-bottom flask (prebaked on vacuum to exclude any moisture) equipped with nitrogen tube, reflux condenser, magnetic stirrer and Dean-Stark trap was charged with $0.218 \mathrm{~g}$ of PMDA (1 mmol) and $3 \mathrm{~mL}$ of NMP/THF (1:1) mixture. Then $0.250 \mathrm{~g}$ of PDMS $(0.1 \mathrm{mmol})$ dissolved in $2 \mathrm{~mL}$ of THF was added slowly to the dianhydride solution. After stirring the mixture for $1 \mathrm{hr}$, $0.288 \mathrm{~g}$ of 2APX $(0.9 \mathrm{mmol})$ dissolved in $2 \mathrm{~mL}$ NMP was added and allowed to stir at room temperature for $16 \mathrm{hrs}$. The resulting poly(amic acid) solution was imidized by heating in a mixture of toluene/ NMP (2:5) at reflux temperature for $8 \mathrm{hrs}$. The toluene was distilled off under vacuum, the solution was cooled to room temperature and poured in a large quantity of water to give a rubbery material, which was filtered and dried in vacuum oven at $80^{\circ} \mathrm{C}$ for $24 \mathrm{hrs}$. In the same way BTDA-2APXPDMS, ODPA-2APX-PDMS and 6FDA-2APXPDMS copolyimides were synthesized by using BTDA, ODPA and 6FDA respectively according to Figure $2 b$.

\section{Results and discussion \\ 3.1. Synthesis and characterization of monomer}

The ether-based diamine $\alpha, \alpha^{\prime}$-bis(2-aminophenoxy)p-xylene (2APX) was synthesized via a two-step approach according to scheme shown in Figure 1. Firstly, dinitro compound $\alpha, \alpha^{\prime}$-bis(2-nitrophenoxy)p-xylene (2NPX) was synthesized by the Williamson's etherification of 2-nitrophenol with 1,4-bis(chloromethyl)benzene in dimethylformamide catalysed by anhydrous potassium carbonate. Then the 2NPX was reduced to corresponding diamine 2APX with hydrazine monohydrate and $\mathrm{Pd} / \mathrm{C}$ in ethanol. The structures of 2NPX and 2APX were confirmed by FTIR, ${ }^{1} \mathrm{H}$ NMR, ${ }^{13} \mathrm{C}$ NMR spectroscopic studies, elemental and single crystal X-ray analysis. Data obtained from these techniques is presented in Table 1. The FTIR spectrum of 2NPX 


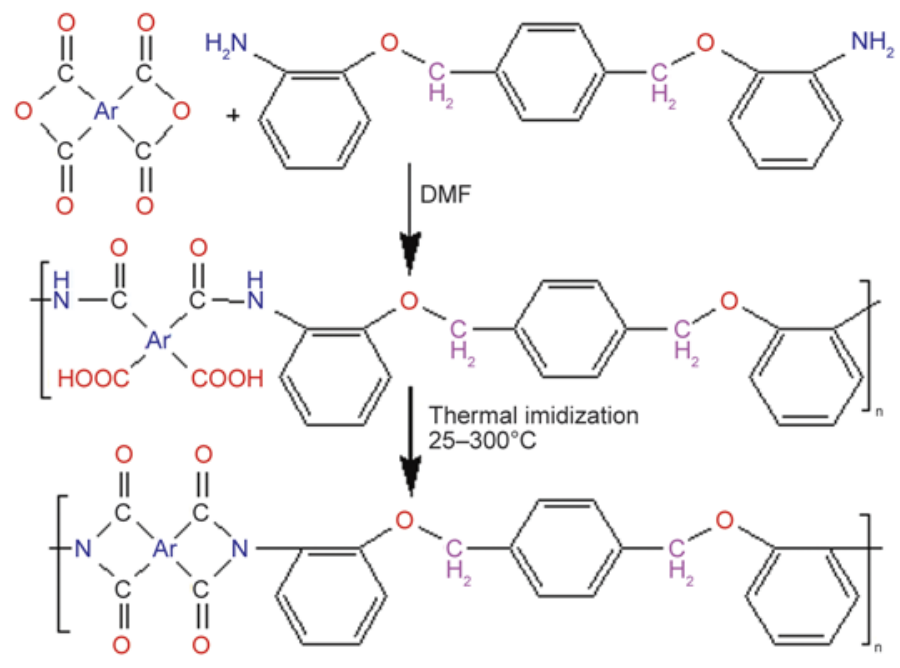

a)

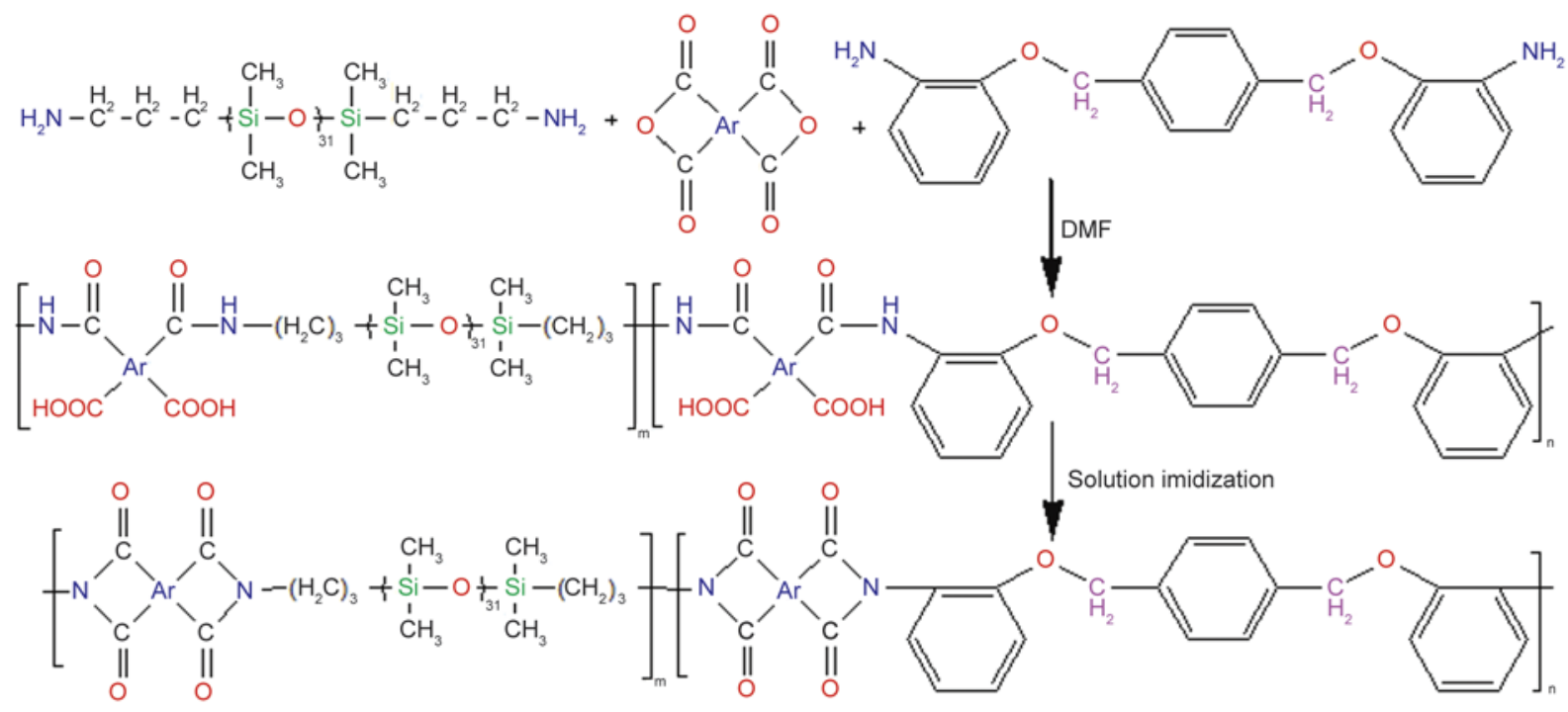
b)

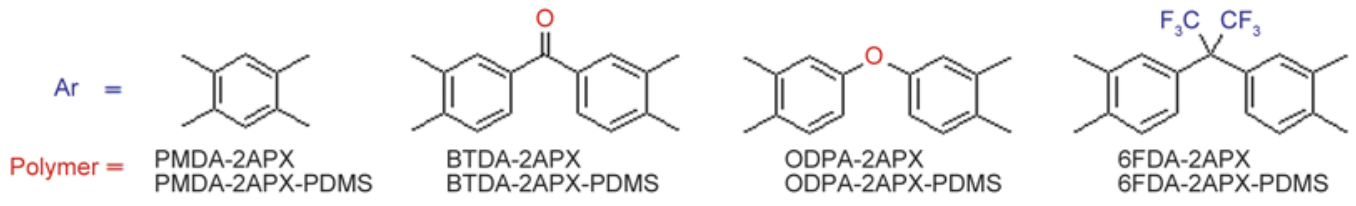

Figure 2. Scheme for synthesis of polyimides (a) and poly(imide siloxane) copolymers (b)

Table 1. FTIR, NMR and elemental analysis data of 2NPX and 2APX

\begin{tabular}{|c|c|c|}
\hline Technique & 2NPX & 2APX \\
\hline FTIR & $\begin{array}{l}3114(\mathrm{Ar}-\mathrm{H}), 2879\left(\mathrm{CH}_{2}\right), 1580\left(\mathrm{NO}_{2} \text { asym }\right), \\
1342\left(\mathrm{NO}_{2} \text { sym }\right), 1253(\mathrm{C}-\mathrm{O}-\mathrm{C})\end{array}$ & $\begin{array}{l}3460,3435\left(\mathrm{NH}_{2}\right), 3056(\mathrm{Ar}-\mathrm{H}), 2865\left(\mathrm{CH}_{2}\right), \\
1275(\mathrm{C}-\mathrm{O}-\mathrm{C})\end{array}$ \\
\hline${ }^{1} \mathrm{H}$ NMR & $\begin{array}{l}7.90\left(1 \mathrm{H}, \mathrm{m}, \mathrm{H}^{3}\right), 7.68-7.63\left(1 \mathrm{H}, \mathrm{m}, \mathrm{H}^{5}\right) \\
7.50-7.44\left(3 \mathrm{H}, \mathrm{m}, \mathrm{H}^{4}, \mathrm{H}^{9}, \mathrm{H}^{9}\right), 7.16-7.11\left(1 \mathrm{H}, \mathrm{m}, \mathrm{H}^{6}\right) \\
5.33\left(2 \mathrm{H}, \mathrm{s}, \mathrm{H}^{7,7}\right)\end{array}$ & $\begin{array}{l}7.51\left(2 \mathrm{H}, \mathrm{s}, \mathrm{H}^{9}, \mathrm{H}^{9^{\prime}}\right), 6.89-6.86\left(1 \mathrm{H}, \mathrm{m}, \mathrm{H}^{4}\right), \\
6.70-6.68\left(2 \mathrm{H}, \mathrm{m}, \mathrm{H}^{5}, \mathrm{H}^{6}\right), 6.55-6.49\left(1 \mathrm{H}, \mathrm{m}, \mathrm{H}^{3}\right), \\
5.09\left(2 \mathrm{H}, \mathrm{s}, \mathrm{H}^{7,7^{\prime}}\right), 4.74\left(2 \mathrm{H}, \mathrm{s},-\mathrm{NH}_{2}\right)\end{array}$ \\
\hline${ }^{13} \mathrm{C}$ NMR & $\begin{array}{l}151.2\left(\mathrm{C}_{1}\right), 140.2\left(\mathrm{C}_{8}\right), 136.3\left(\mathrm{C}_{5}\right), 135.2\left(\mathrm{C}_{2}\right), 128.7\left(\mathrm{C}_{9}\right), \\
125.5\left(\mathrm{C}_{3}\right), 121.3\left(\mathrm{C}_{4}\right), 116.4\left(\mathrm{C}_{6}\right), 70.50\left(\mathrm{C}_{7}\right)\end{array}$ & $\begin{array}{l}145.7\left(\mathrm{C}_{1}\right), 138.4\left(\mathrm{C}_{8}\right), 137.4\left(\mathrm{C}_{2}\right), 128.2\left(\mathrm{C}_{9}\right), 121.6\left(\mathrm{C}_{4}\right), \\
116.6\left(\mathrm{C}_{5}\right), 114.6\left(\mathrm{C}_{3}\right), 112.6\left(\mathrm{C}_{6}\right), 69.5\left(\mathrm{C}_{7}\right)\end{array}$ \\
\hline Elemental & $\begin{array}{l}\% \text { Calcd: } \mathrm{C}=63.16, \mathrm{H}=4.21, \mathrm{~N}=7.37 \\
\% \text { found: } \mathrm{C}=62.93, \mathrm{H}=4.18, \mathrm{~N}=7.25\end{array}$ & $\begin{array}{l}\% \text { Calcd: } \mathrm{C}=75.00, \mathrm{H}=6.25, \mathrm{~N}=8.75 \\
\% \text { found: } \mathrm{C}=74.60, \mathrm{H}=6.35, \mathrm{~N}=8.50\end{array}$ \\
\hline
\end{tabular}

displayed the characteristic absorption bands of ether linkage $(\mathrm{C}-\mathrm{O}-\mathrm{C})$ at $1253 \mathrm{~cm}^{-1}$ and nitro functionality $\left(\mathrm{NO}_{2}\right)$ at 1580 and $1342 \mathrm{~cm}^{-1}$ correspon- ding to asymmetric and symmetric stretches respectively. The reduction of $2 \mathrm{NPX}$ to $2 \mathrm{APX}$ was confirmed by disappearance of $\mathrm{NO}_{2}$ absorptions and 
advent of typical $\mathrm{N}-\mathrm{H}$ stretching bands for primary amines at 3460 and $3435 \mathrm{~cm}^{-1}$ in the FTIR spectrum of 2APX. Structures of 2NPX and 2APX were also elucidated by ${ }^{1} \mathrm{H}$ NMR spectroscopic technique. Phenyl protons were verified by the appearance of signals in the characteristic region between 6$8 \mathrm{ppm}$ according to substituents attached. The protons of aromatic ring at ortho and para positions of nitro group $\left(\mathrm{H}^{3 \& 5}\right)$ resonated at the farthest downfield (7.90-7.63 ppm) in the ${ }^{1} \mathrm{H}$ NMR spectrum of 2NPX which is attributed to the deshielding engendered by electron withdrawing effect of $\mathrm{NO}_{2}$ group. However, in case of 2APX resonance signals for these protons were shifted to upfield region (6.70$6.49 \mathrm{ppm}$ ) which is clear evidence in favor of nitro group reduction to amine. Moreover, presence of amine functionality in the structure of 2APX was also certified by the advent of two protons singlet at $4.74 \mathrm{ppm}$ in the ${ }^{1} \mathrm{H}$ NMR spectrum as shown in Figure 3a. Appearance of two protons singlets at 5.33 and $5.09 \mathrm{ppm}$ for 2NPX and 2APX respectively due to methylene protons $\left(\mathrm{H}^{7}\right)$ proves the formation of ether linkage. ${ }^{13} \mathrm{C}$ NMR spectroscopic study also supported the structures of compounds as the characteristic signals for all the carbon atoms were observed as shown in ${ }^{13} \mathrm{C}$ NMR spectrum of 2APX presented in Figure 3b. Like the proton NMR, a slight upfield shift observed for carbon atoms at ortho and para positions of $\mathrm{NH}_{2}$ group $\left(\mathrm{C}_{3 \& 5}\right)$ in the ${ }^{13} \mathrm{C}$ NMR spectrum of $2 \mathrm{APX}$ as compared to $2 \mathrm{NPX}$
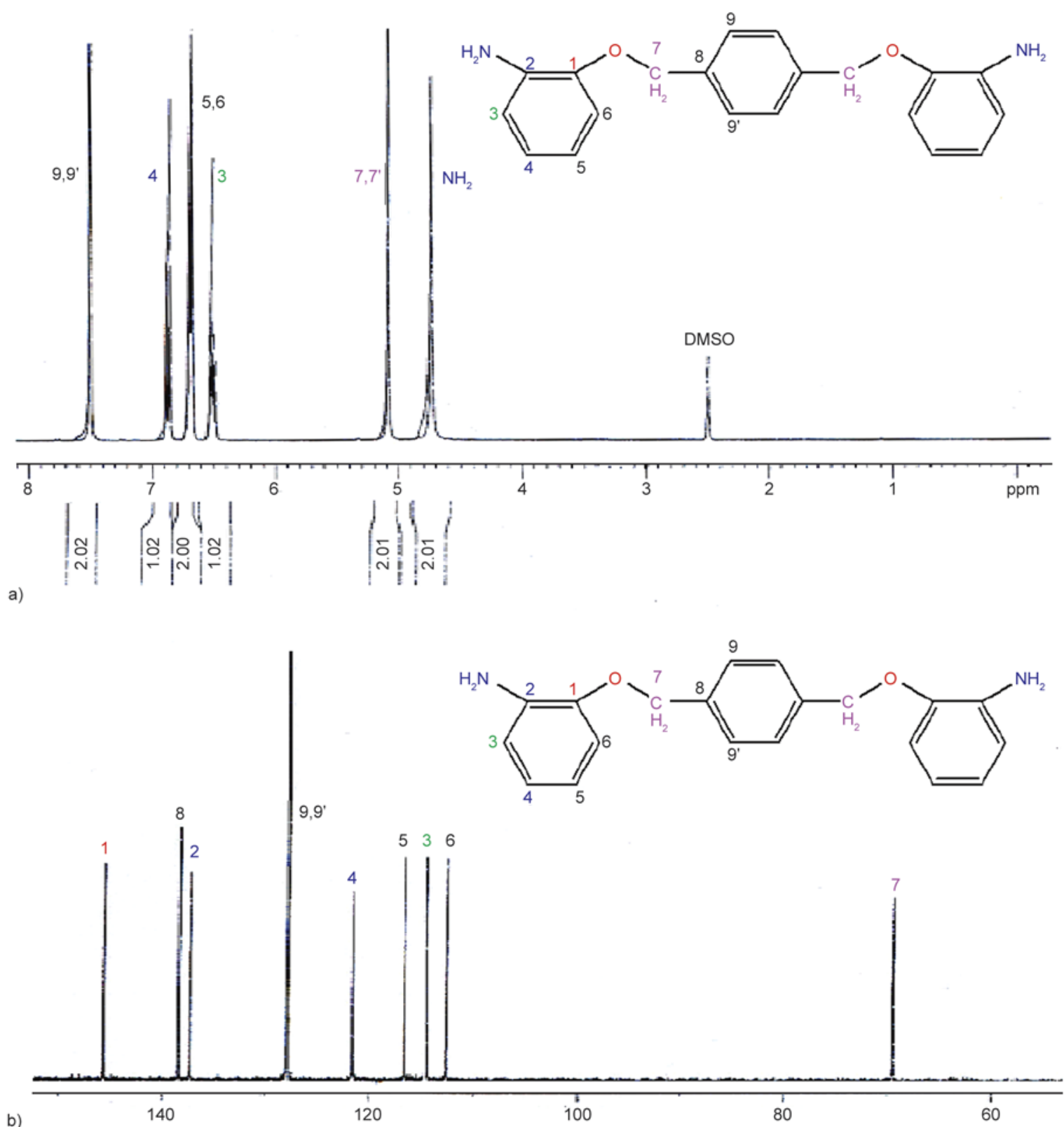

Figure 3. ${ }^{1} \mathrm{H}$ NMR (a) and ${ }^{13} \mathrm{C}$ NMR (b) spectra of $2 \mathrm{APX}$ 
is attributed to the electron donating effect of amine group. This also supports the successful conversion of $\mathrm{NO}_{2}$ group to $\mathrm{NH}_{2}$ moiety. Elemental analysis shows that found and calculated ratios of carbon $(\mathrm{C})$, hydrogen $(\mathrm{H})$ and nitrogen $(\mathrm{N})$ are in good agreement with each other. It also supports the successful synthesis of monomers.

Single crystal X-ray analysis also confirmed the structure of 2NPX and 2APX. Crystals of compounds suitable for single crystal X-ray analysis were developed by slow evaporation of DMSO and ethanol respectively at room temperature to identify their structures. Crystallographic data was collected at $150(2) \mathrm{K}$ on a Bruker Apex II CCD diffractometer using Mo-K $\alpha$ radiation $(\alpha=0.71073 \AA)$. The structure was solved by direct methods and refined on $\mathrm{F}^{2}$ using all the reflections [31]. All the nonhydrogen atoms were refined using anisotropic atomic displacement parameters and hydrogen atoms bonded to carbon were inserted at calculated positions using a riding model. The amine hydrogens in 2APX were located from difference maps and their coordinates refined. Parameters for data collection and refinement are summarised in Table 2. The structures of 2NPX and 2APX are shown in Figure 4 and 5 respectively. The dinitro molecule (2NPX) is centrosymmetric having no obvious $\pi-\pi$ stacking interactions in the lattice although there are some weak

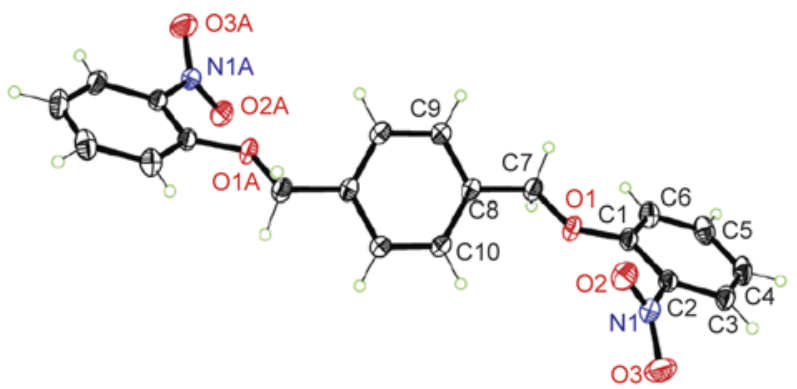

Figure 4. Molecular structure of 2NPX. Non-hydrogen atoms shown with $50 \%$ probability ellipsoids. Atoms with suffix 'A' generated by symmetry operation 1-x, 1-y, 1-z.

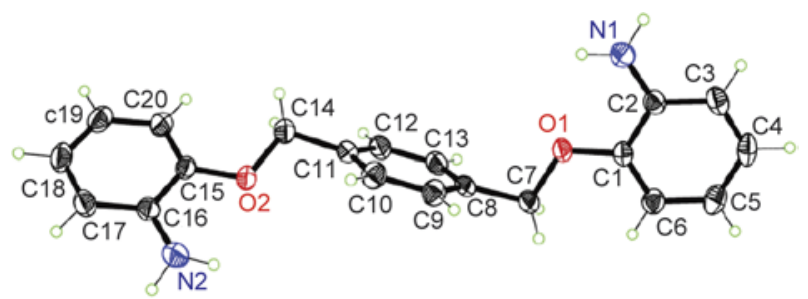

Figure 5. Molecular structure of 2APX. Non-hydrogen atoms shown with $50 \%$ probability ellipsoids.

$\mathrm{CH}^{\cdots \cdot \mathrm{O}}$ interactions. The central ring makes an angle of $52.41(5)^{\circ}$ with the outer rings. The molecule of 2APX has no internal symmetry since the terminal rings are at different angles to the central phenyl group (78.87(4) and 34.52(4) ${ }^{\circ}$ for rings containing $\mathrm{N} 1$ and $\mathrm{N} 2$, respectively). No convincing hydrogen bonding was observed in the structure,

Table 2. Crystal data and structure refinement for 2NPX and 2APX

\begin{tabular}{|c|c|c|}
\hline Parameter & 2NPX & 2APX \\
\hline Empirical formula & $\mathrm{C}_{20} \mathrm{H}_{16} \mathrm{~N}_{2} \mathrm{O}_{6}$ & $\mathrm{C}_{20} \mathrm{H}_{20} \mathrm{~N}_{2} \mathrm{O}_{2}$ \\
\hline Formula weight & 380.35 & 320.38 \\
\hline Temperature & $150(2) \mathrm{K}$ & $150(2) \mathrm{K}$ \\
\hline Wavelength & $0.71073 \AA$ & $0.71073 \AA$ \\
\hline Crystal system & Monoclinic & Triclinic \\
\hline Space group & $P 2_{1} / \mathrm{n}$ & $P \overline{1}$ \\
\hline Unit cell dimensions & $\begin{array}{ll}a=7.4203(4) \AA & \alpha=90^{\circ} \\
b=11.7771(6) \AA & \beta=90.8180(10)^{\circ} \\
c=9.7275(5) \AA & \gamma=90^{\circ}\end{array}$ & $\begin{array}{lll}a=8.7516(6) \AA & \alpha=64.8160(10)^{\circ} \\
b=10.1550(7) \AA & \beta=68.0410(10)^{\circ} \\
c=11.0313(8) \AA & \gamma=77.8430(10)^{\circ}\end{array}$ \\
\hline Volume & $850.00(8) \AA^{3}$ & $821.28(10) \AA^{3}$ \\
\hline $\mathrm{Z}$ & 2 & 2 \\
\hline Density (calculated) & $1.486 \mathrm{Mg} / \mathrm{m}^{3}$ & $1.296 \mathrm{Mg} / \mathrm{m}^{3}$ \\
\hline Absorption coefficient & $0.112 \mathrm{~mm}^{-1}$ & $0.084 \mathrm{~mm}^{-1}$ \\
\hline $\mathrm{F}(000)$ & 396 & 340 \\
\hline Crystal size & $0.37 \times 0.21 \times 0.17 \mathrm{~mm}^{3}$ & $0.60 \times 0.24 \times 0.21 \mathrm{~mm}^{3}$ \\
\hline Crystal description & orange block & colourless rhomb \\
\hline Theta range for data collection & 2.72 to $30.56^{\circ}$ & 2.15 to $28.34^{\circ}$ \\
\hline Reflections collected & 9717 & 8491 \\
\hline Independent reflections & $2583[R($ int $)=0.0224]$ & $4059[R(\mathrm{int})=0.0196]$ \\
\hline$R\left[F^{2}>2 \sigma\left(F^{2}\right)\right]$ & 0.042 & 0.043 \\
\hline$w R\left(F^{2}\right)$ & 0.119 & 0.113 \\
\hline GooF & 1.06 & 1.07 \\
\hline CCDC number & 1056786 & 1056787 \\
\hline
\end{tabular}




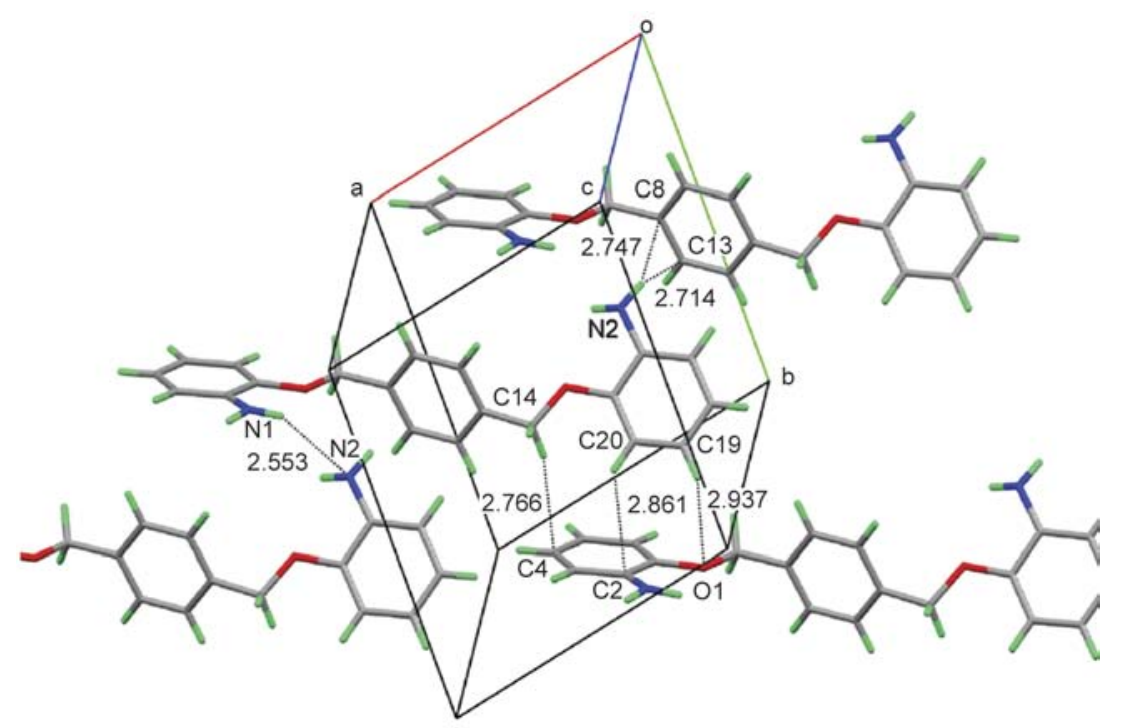

Figure 6. Weak intermolecular interactions in the lattice of 2APX

although there are some $\mathrm{NH}^{\cdots \cdot} \pi$ and $\mathrm{CH}^{\cdots \cdot} \pi$ interactions as shown in Figure 6 and these seem to be the most significant intermolecular effects.

\subsection{Synthesis and characterization of polyimides and copolyimides}

The newly designed diamine 2APX was condensed with four commercially available dianhydrides i.e. PMDA, BTDA, ODPA, 6FDA to synthesize simple polyimides. Then this diamine was polymerized with same dianhydrides along with aminopropyl terminated polydimethylsiloxane (PDMS) oligomer of $M_{\mathrm{n}}=2500$ to synthesize poly(imide siloxane) copolymers. The synthesis of the polyimides and copolyimides was confirmed by FTIR and ${ }^{1} \mathrm{H}$-NMR spectroscopic techniques. FTIR spectra of polyimides displayed characteristic absorption bands associated with five membered imide ring around 1780 and $1715 \mathrm{~cm}^{-1}$ attributed to asymmetric and symmetric $\mathrm{C}=\mathrm{O}$ stretches respectively, along with $\mathrm{C}-\mathrm{N}$ stretching absorptions around $1375 \mathrm{~cm}^{-1}$. The completion of the reaction i.e. conversion of polyamic acid to fully cyclized polyimide was confirmed by disappearance of: carboxyl and $\mathrm{NH}$ bands in the region of $3100-3500 \mathrm{~cm}^{-1}$ (at the polyamic acid stage) and the appearance of the characteristic absorption bands of the imide ring accompanied by shifting of carbonyl stretching vibrations towards higher frequency i.e. from 1650 to $1715 \mathrm{~cm}^{-1}$. However, polyimide derived from BTDA displayed absorption bands around $1645 \mathrm{~cm}^{-1}$ along with typical peaks of imide group even after imidization which is attributed to the presence of ketonic carbonyl moiety in its structure. Similarly appearance of characteristic peaks for siloxane moieties i.e. $\mathrm{Si}-\mathrm{O}-\mathrm{Si}$ and $\mathrm{Si}-\mathrm{CH}_{3}$ around 1080 and $792 \mathrm{~cm}^{-1}$ respectively along with typical peaks of imide structure in the FTIR spectra of PDMS containing copolyimides confirmed the synthesis of poly(imide siloxane) copolymers. FTIR data of polyimides and copolyimides is listed in Table 3. Representative FTIR spectra of polyimide PMDA-2APX at poly(amic acid) stage and after imidization are shown in Figure 7.

Table 3. FTIR data of polyimides and copolyimides

\begin{tabular}{|l|c|c|c|c|c|c|c|c|}
\hline \multirow{2}{*}{\multicolumn{1}{c}{ Polymer }} & \multicolumn{2}{|c|}{ Before imidization } & \multicolumn{7}{c|}{ After imidization } \\
\cline { 2 - 10 } & $\mathbf{O H}, \mathbf{N H}$ & $\mathbf{C =} \mathbf{O}(\mathbf{a m i d e})$ & $\mathbf{O H}, \mathbf{N H}$ & $\mathbf{C =} \mathbf{O}$ (imide) & $\mathbf{C}-\mathbf{N}$ (imide) & Si-O-Si & $\mathbf{S i}_{-} \mathbf{C H}_{\mathbf{3}}$ & $\mathbf{C H}_{\mathbf{3}}$ \\
\hline PMDA-2APX & 3524 & 1627 & - & 1704,1779 & 1349 & - & - & - \\
\hline PMDA-2APX-PDMS & 3435 & 1643 & - & 1722,1778 & 1376 & 1088 & 792 & 2961 \\
\hline BTDA-2APX & 3432 & 1655 & - & 1716,1779 & 1373 & - & - & - \\
\hline BTDA-2APX-PDMS & 3446 & 1652 & - & 1717,1780 & 1378 & 1087 & 794 & 2961 \\
\hline ODPA-2APX & 3465 & 1660 & - & 1715,1777 & 1374 & - & - & - \\
\hline ODPA-2APX-PDMS & 3462 & 1637 & - & 1717,1780 & 1377 & 1078 & 792 & 2961 \\
\hline 6FDA-2APX & 3496 & 1655 & - & 1716,1786 & 1378 & - & - & - \\
\hline 6FDA-2APX-PDMS & 3458 & 1648 & - & 1716,1785 & 1380 & 1094 & 793 & 2962 \\
\hline
\end{tabular}



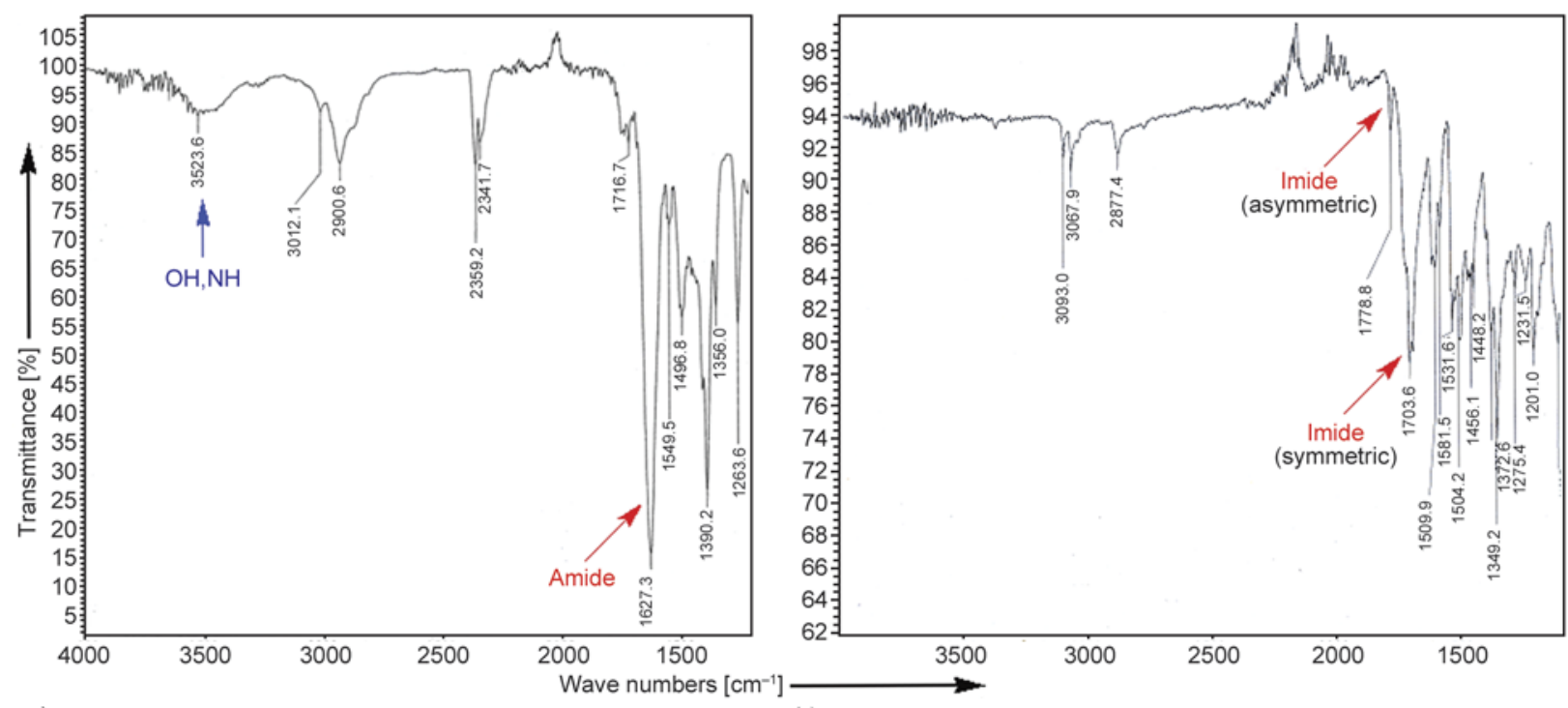

a)

b)

Figure 7. FTIR spectra of PMDA-2APX at poly(amic acid) stage (a) and after imidization (b)

Soluble polymers i.e. 6FDA-2APX, 6FDA-2APXPDMS and ODPA-2APX-PDMS were also characterized by ${ }^{1} \mathrm{H}$ NMR spectroscopy and data obtained is presented in Table 4. Appearance of characteristic signals of aromatic protons along with methyl- ene protons supported the proposed structures of polymers. Representative ${ }^{1} \mathrm{H}$ NMR spectrum of the 6FDA-2APX with the assignment of protons is shown in Figure 8 which is in complete agreement with the proposed structure of polyimide. In case of

Table 4. ${ }^{1} \mathrm{H}$ NMR data of polymers

\begin{tabular}{|c|c|c|c|c|c|c|}
\hline \multirow{3}{*}{ Polymer } & \multicolumn{6}{|c|}{${ }^{1} \mathrm{H}$ NMR (DMSO-d 6 ) chemical shifts in ppm } \\
\hline & \multirow{2}{*}{$\mathbf{A r}-\mathbf{H}$} & \multirow{2}{*}{$\mathrm{O}-\mathrm{CH}_{2}$} & \multicolumn{3}{|c|}{$\mathrm{CH}_{2}$} & \multirow{2}{*}{$\mathrm{Si}-\mathrm{CH}_{3}$} \\
\hline & & & $\mathbf{H}^{10}$ & $\mathbf{H}^{11}$ & $\mathrm{H}^{12}$ & \\
\hline 6FDA-2APX & $8.38-7.03\left(9 \mathrm{H}, \mathrm{m}, \mathrm{H}^{1,2,3,4,5,6,7,9,9^{\prime}}\right)$ & 5.08 & - & - & - & - \\
\hline 6FDA-2APX-PDMS & $8.43-7.18\left(9 \mathrm{H}, \mathrm{m}, \mathrm{H}^{1,2,3,4,5,6,7,9,9^{\prime}}\right)$ & 5.23 & 3.58 & 1.60 & 0.47 & -0.001 \\
\hline ODPA-2APX-PDMS & $8.16-7.35\left(9 \mathrm{H}, \mathrm{m}, \mathrm{H}^{1,2,3,4,5,6,7,9,9^{\prime}}\right)$ & 5.12 & 3.62 & 1.59 & 0.48 & -0.053 \\
\hline
\end{tabular}<smiles>CN1C(=O)c2ccc(C(c3ccc4c(c3)C(=O)N(c3cccc(OCc5ccc(COc6ccccc6)cc5)c3)C4=O)(C(F)(F)F)C(F)(F)F)cc2C1=O</smiles>
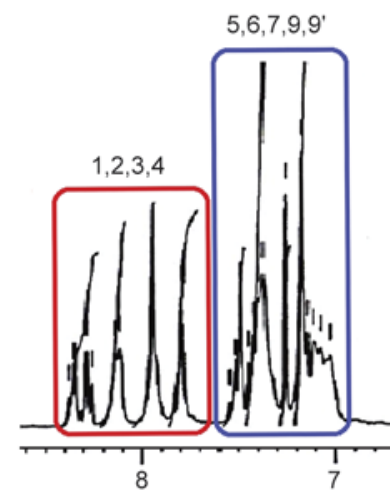

Figure 8. ${ }^{1} \mathrm{H}$ NMR Spectrum of 6FDA-2APX 
6FDA-2APX, resonance signals in the range of 8.38-7.74 ppm are assigned to the phenyl protons of dianhydride segment i.e. $\mathrm{H}^{1}, \mathrm{H}^{2}$ and $\mathrm{H}^{3}$ in the polymer chain. This downfield shift is attributed to electron withdrawing nature of carbonyl groups present in it. Aromatic protons of the diamine fragment appeared slightly upfield between 7.48-7.03 ppm. Two proton singlet signal present at $5.08 \mathrm{ppm}$ in spectrum is ascribed to methylene group present in structure inherited from diamine. The disappearance of signals for amine protons and downfield shift observed for phenyl proton adjacent to $-\mathrm{NH}_{2}$ functionality ( $\mathrm{H}^{3}$ in diamine and $\mathrm{H}^{4}$ in polymer) from 6.52 to $7.74 \mathrm{ppm}$ (owing to electron withdrawing effect of dianhydride segment) as compared to ${ }^{1} \mathrm{H}$ NMR spectrum of 2APX, validated the establishment of imide linkage from amine and dianhydride. Moreover, imidization of poly(amic acid) was also confirmed by the fact that ${ }^{1} \mathrm{H}$ NMR spectra of polymer showed no signals in the characteristic region of amide protons i.e. between 9-11 ppm. In addition to aforementioned peaks, ${ }^{1} \mathrm{H}$ NMR spectra of 6FDA2APX-PDMS and ODPA-2APX-PDMS displayed resonance signals around $3.60,1.60,0.47$ and $0.00 \mathrm{ppm}$ which are characteristic peaks for: methylene protons adjacent to imide ring $\left(\mathrm{H}^{10}\right)$, central methylene of propyl $\left(\mathrm{H}^{11}\right)$, methylene next to $\mathrm{Si}\left(\mathrm{H}^{12}\right)$ and methyl protons adjacent to $\mathrm{Si}\left(\mathrm{H}^{13}\right)$ respectively. These signals suggest that aminopropyl terminated polydimethylsiloxane (PDMS) segments have been incorporated successfully into the polyimide chain.

\subsection{Organosolubility of polymers}

The solubility of polymers was tested quantitatively $(0.1 \mathrm{~g} / 5 \mathrm{~mL})$ in organic solvents like DMSO, DMF, DMAc, NMP and also in $\mathrm{H}_{2} \mathrm{SO}_{4}$. It was found that the simple polyimides except that synthesized from 4,4'-(hexafluoroisopropylidene) diphthalic anhy- dride i.e. 6FDA-2APX were insoluble in these solvents. This is attributed to ultra-strong intermolecular interactions and good packing ability of the polymer chains which suggests their semi-crystalline behavior and it is also proved by their WAXRD analysis. Under normal circumstances, intermolecular interactions in the polyimide chains occur between electron-donating diamine segments and electron-withdrawing dianhydride moieties in the polymer chain. But in case of polyimides under discussion, in addition to these interactions, there are some other intermolecular effects responsible for enhancing chain packing ability. Luckily, we got the single crystal of 2APX and it was observed during X-ray analysis that $\mathrm{CH}^{\cdots} \cdot \pi$ interactions are present between the 2APX molecules as shown in Figure 6. Therefore, polyimides synthesized from this diamine displayed insolubility in spite of having ether linkage in their structure. Moreover, the existence of a large number of benzene rings in polymer backbone without bulky side groups tremendously improved the structure regularity and consequently reduced the solubility. The solubility of 6FDA2APX is attributed to steric hindrance of bulky $\mathrm{CF}_{3}$ groups. These groups increased the disorder in the chains and hindered compact chain stacking thus reducing the chain-chain interactions. This resulted in increase of free volume and consequently better penetration of solvent molecules into the polymer chains that enhanced solubility. However, solubility of other polyimides was improved by the incorporation of flexible PDMS segment in the backbone as it reduced the packing ability of polymer chains. Solubility data of simple polyimides and poly(imide siloxane) copolymers is given in Table 5 and results show that polyimides which were insoluble, have shown partial solubility after copolymerization. Also the polyimide ODPA-2APX which was partially soluble before copolymerization, completely

Table 5. Solubility data of polymers

\begin{tabular}{|c|c|c|c|c|c|}
\hline Polymer & DMSO & DMF & DMAc & NMP & $\mathrm{H}_{2} \mathrm{SO}_{4}$ \\
\hline PMDA-2APX & - & - & - & - & + \\
\hline PMDA-2APX-PDMS & + & + & + & + & ++ \\
\hline BTDA-2APX & - & - & - & - & + \\
\hline BTDA-2APX-PDMS & + & + & + & + & ++ \\
\hline ODPA-2APX & + & + & + & + & + \\
\hline ODPA-2APX-PDMS & ++ & ++ & ++ & ++ & ++ \\
\hline 6FDA-2APX & ++ & ++ & ++ & ++ & ++ \\
\hline 6FDA-2APX-PDMS & ++ & ++ & ++ & ++ & ++ \\
\hline
\end{tabular}

++ : (soluble on heating), + : (slightly soluble on heating), - : (insoluble) 
solubilized after introduction of flexible PDMS segment in the backbone. This improvement in solubility of copolyimides was expected as reported in literature $[32,33]$.

\subsection{Wide angle $X$-ray diffraction analysis (WAXRD)}

The crystallinity of the polyimides and copolyimides was examined by wide angle X-ray diffraction analysis with 3040/60 X'Pert PRO diffractometer in the region of $2 \theta=5-50^{\circ}$ at room temperature using the polyimide powder obtained as samples. WAXRD diffractograms shown in Figure 9 illustrate the semi-crystalline nature of polyimides and almost amorphous morphology of copolymers. Among the polyimides, the least crystalline behavior was observed for 6FDA-2APX which is attributed to reduction in chain packing efficiency due to bulky $\mathrm{CF}_{3}$ groups. Incorporation of flexible PDMS segment led to decline in crystallinity of polyimides as it discouraged the chain symmetry thus making it harder for them to pack into the crystal lattice hence reveals a large decrease in crystallinity [34]. These results also support the observed insolubility of polyimides and partial solubility of copolyimides as the amorphous nature of the resulting polymers endows them a good solubility [35].

\subsection{Thermal properties of polymers}

The thermal properties of the polyimides were evaluated by means of TGA. It was observed that copolyimides are thermally less stable as compared to corresponding polyimides. The temperature at $10 \%$ weight loss $\left(T_{10}\right)$, an important criterion for evaluation of thermal stability was in the range of 386$405^{\circ} \mathrm{C}$ for polyimides while for poly(imide silox-

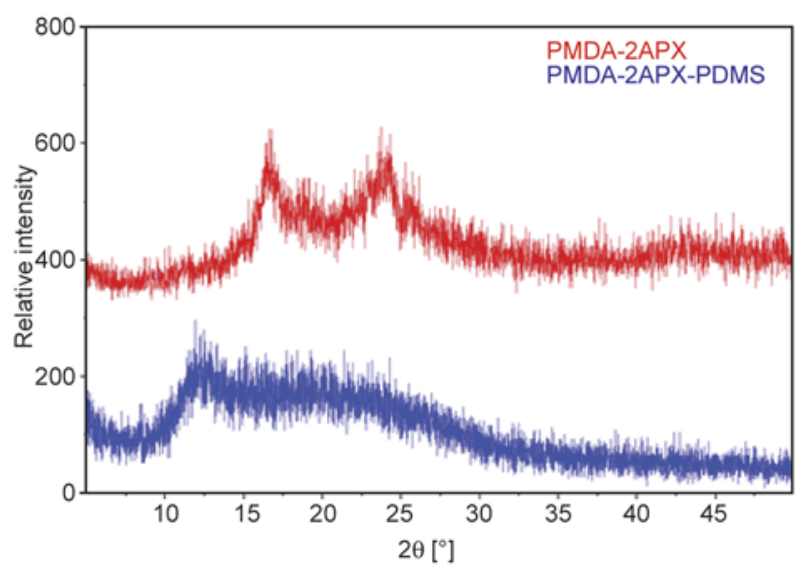

Figure 9. WAXRD diffractograms of polyimides and copolyimides

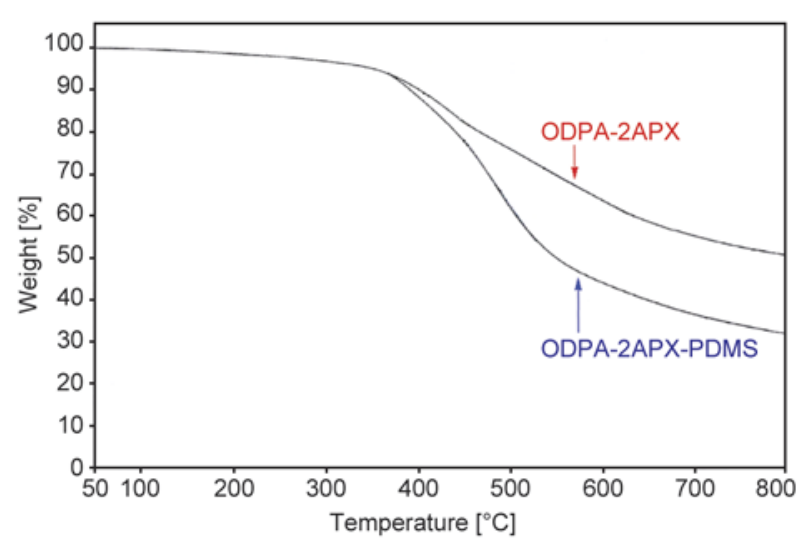

Figure 10. Thermograms of ODPA-2APX and ODPA2APX-PDMS

Table 6. Thermal analysis data of polymers

\begin{tabular}{|l|c|c|c|}
\hline \multicolumn{1}{|c|}{ Polymer } & $\begin{array}{c}\mathbf{T}_{\mathbf{1 0}} \\
{\left[{ }^{\mathbf{C}} \mathbf{C}\right]^{\mathbf{a}}}\end{array}$ & $\begin{array}{c}\mathbf{T}_{\mathbf{m a x}} \\
{\left[{ }^{\circ} \mathbf{C}\right]^{\mathbf{b}}}\end{array}$ & $\begin{array}{c}\mathbf{R}_{\mathbf{8 0 0}} \\
{\left[{ }^{\circ} \mathbf{C}\right]^{\mathbf{c}}}\end{array}$ \\
\hline PMDA-2APX & 395 & 565 & 48 \\
\hline PMDA-2APX-PDMS & 386 & 525 & 34 \\
\hline BTDA-2APX & 405 & 570 & 51 \\
\hline BTDA-2APX-PDMS & 403 & 515 & 39 \\
\hline ODPA-2APX & 400 & 540 & 52 \\
\hline ODPA-2APX-PDMS & 390 & 495 & 32 \\
\hline 6FDA-2APX & 386 & 523 & 47 \\
\hline 6FDA-2APX-PDMS & 368 & 483 & 31 \\
\hline
\end{tabular}

${ }^{a}$ temperature at $10 \%$ weight loss

${ }^{b}$ temperature at which maximum degradation occurs

${ }^{c}$ residual mass $(\mathrm{wt} \%)$ at $800^{\circ} \mathrm{C}$

ane) copolymers, it ranged between $368-403^{\circ} \mathrm{C}$. Temperature range of maximum weight loss $\left(T_{\max }\right)$ was $523-570^{\circ} \mathrm{C}$ and $483-525^{\circ} \mathrm{C}$ for polyimides and copolyimides respectively. Residual mass (wt\%) at $800^{\circ} \mathrm{C}\left(R_{800}\right)$ was also measured and found between $47-52 \%$ for polyimides and $31-39 \%$ for siloxanecontaining copolyimides. This decrease in thermal stability of coployimides is ascribed to the presence of thermally less stable aliphatic portion in the form of PDMS within the copolymer backbone. Representative thermograms of polyimide ODPA-2APX and copolyimide ODPA-2APX-PDMS are shown in Figure 10. Thermal stability data for polyimides and copolyimides is listed in the Table 6 and results reveal that these polymers exhibit good thermal stability with a slight weight loss up to $400^{\circ} \mathrm{C}$. This could be attributed to phenylation of the backbone and formation of imide units in the structure of polymers.

\subsection{Viscometric analysis}

The inherent viscosities of the soluble polyimides and copolyimides synthesized were determined by 
Table 7. Viscometric and light scattering data

\begin{tabular}{|l|c|c|c|}
\hline \multicolumn{1}{|c|}{ Polymer } & $\begin{array}{c}\boldsymbol{\eta}_{\text {inh }} \\
{[\mathbf{d L} / \mathbf{g}]}\end{array}$ & $\begin{array}{c}\mathbf{M}_{\mathbf{w}} \\
{[\mathbf{g} / \mathbf{m o l e}]}\end{array}$ & $\begin{array}{c}\mathbf{R}_{\mathbf{g}} \\
{[\mathbf{n m}]}\end{array}$ \\
\hline 6FDA-2APX & 0.29 & $3.52 \times 10^{5}$ & 53 \\
\hline 6FDA-2APX-PDMS & 0.11 & $8.48 \times 10^{5}$ & 85 \\
\hline ODPA-2APX-PDMS & 0.15 & $3.29 \times 10^{6}$ & 78 \\
\hline
\end{tabular}

$\mathrm{d} n / \mathrm{d} c=0.165 \mathrm{~mL} / \mathrm{g}$

Relative errors: $M_{\mathrm{w}}= \pm 5 \%, R_{\mathrm{g}}= \pm 5 \%$

dissolving $0.2 \mathrm{~g} / \mathrm{dL}$ of sample in DMSO at $25^{\circ} \mathrm{C}$ using Ubbelohde's Viscometer and data obtained is given in Table 7. Inherent viscosity of polymer 6FDA-2APX was found to be $0.29 \mathrm{dL} / \mathrm{g}$. Since the inherent viscosity is a good criterion for estimation of molecular weight, hence polyimide 6FDA-2APX is expected to show reasonable molecular weight. This supposition was supported by laser light scattering analysis as molecular weight of $3.52 \times 10^{5}$ was determined. The $\eta_{\text {inh }}$ was declined to $0.11 \mathrm{dL} / \mathrm{g}$ for copolyimide 6FDA-2APX-PDMS as incorporation of PDMS segment, decreased the rigidity and stiffness of polymer chains owing to its flexible nature. The inherent viscosities of 0.11 and $0.15 \mathrm{dL} / \mathrm{g}$ are reasonable for this kind of copolymers as reported in the literature [36].

\subsection{Laser light scattering analysis}

Molecular weights of polymers were determined using static laser light scattering (SLLS) analysis technique by dissolving $0.8 \mathrm{~g} / \mathrm{dL}$ of sample in DMSO. SLLS measures light intensity as a function of scattering angle and solute concentration and the relationship between the light scattering from a dilute polymer solution and the weight-average molecular weight can be described by the Zimm formalism. This allows the determination of weightaverage molecular weight, radius of gyration and shape information of the solute [37]. The results revealed that copolyimide 6FDA-2APX-PDMS have higher molecular weight than corresponding polyimides (6FDA-2APX). This increase in weight is understandable as high molecular weight PDMS segment $\left(M_{\mathrm{n}}=2500\right)$ is introduced in the polymer chain. Moreover, incorporation of PDMS segment imparts flexibility to chain, hence it can grow to a longer length and consequently molecular weight of polymer increases. Like the molecular weight $\left(M_{\mathrm{w}}\right)$, radius of gyration $\left(R_{\mathrm{g}}\right)$ of copolymers is also longer than simple polymers, which is again attributed to reduction in chain rigidity by PDMS. These results of molecular weight suggest that synthesized diamine

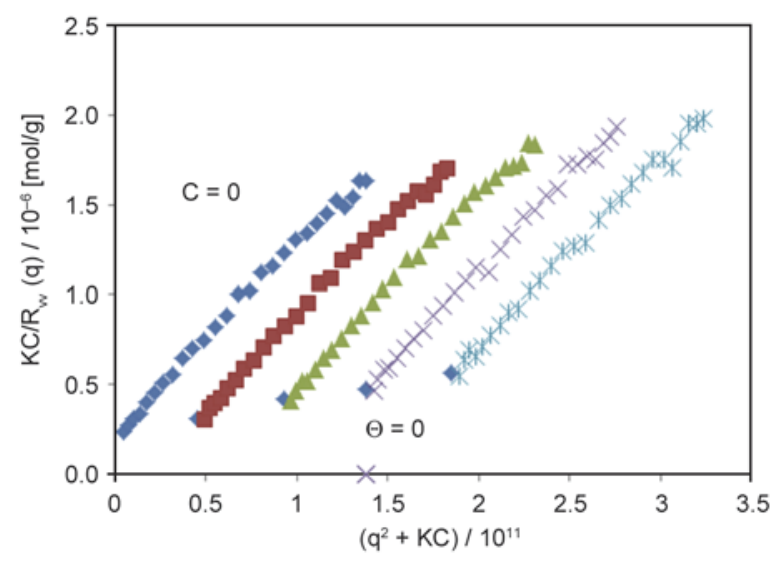

Figure 11. Zimm plot for ODPA-2APX-PDMS at $20^{\circ} \mathrm{C}$

has good tendency to react with dianhydrides. Results obtained from viscometric and laser light scattering of polymers are listed in Table 7 and representative Zimm plot for ODPA-2APX-PDMS is shown in Figure 11.

\section{Conclusions}

Polyimides and poly(imide siloxane) copolymers were synthesized successfully from newly designed diamine monomer 2APX. The structures of diamine and polymers were verified by different techniques. The main objective of the research was to study the properties of polyimides derived from diamine having amino group at ortho position with respect to ether linkage and monitor the influence of aminopropyl terminated polydimethylsiloxane (PDMS) segment on properties of the parent polyimides. In this regard main emphasis was on solubility, crystallinity, thermal stability, viscosity and molecular weight of polymers. Polyimides, except that synthesized from 6FDA, were insoluble in organic solvents, however their solubility was improved after incorporation of siloxane units in the polymer chains. WAXRD pattern showed that polyimides are semicrystalline in nature that was decreased in case of copolyimides. Comparison of data obtained from the thermal study of these polymers showed that poly(imide siloxane) copolymers are thermally less stable than corresponding polyimides. Viscometric analysis revealed that siloxane-containing polyimides are less viscous than simple polymers. Finally, high molecular weight polymers were synthesized successfully by introduction of PDMS segment in the backbone of polymer chain. The observed behavior of polymers suggests that the synthesized polyimides can be used as high temperature and solvent 
resistant materials for applications under severe conditions where excellent thermal stability and resistivity is desired. However poly(imide siloxane) copolymers can be used in applications where improved processability is of prime importance while sacrificing some of thermal stability.

\section{Supplementary Data}

CCDC 1056786 and 1056787 contain the supplementary crystallographic data for this paper. These data can be obtained free of charge from The Cambridge Crystallographic Data Centre via

www.ccdc.cam.ac.uk/data request/cif.

\section{Acknowledgements}

The author would like to acknowledge the Higher Education Commission of Pakistan for providing financial support under Indigenous 5000 Ph.D. Fellowship Program (Phase II). The financial support from University Research Funds (URF) is also greatly acknowledged.

\section{References}

[1] García J. M., García F. C., Serna F., de la Peña J. L.: High-performance aromatic polyamides. Progress in Polymer Science, 35, 623-686 (2010).

DOI: 10.1016/j.progpolymsci.2009.09.002

[2] Gao Y., Zhou Y., He M., Wang H., Cui Y., Zhang T.: Synthesis and characterization of fluorinated polyimides derived from 1,4-bis-[4-amino-2-(trifluoromethyl)phenoxy] benzene/tetrafluoride benzene. Designed Monomers and Polymers, 17, 590-600 (2014). DOI: $10.1080 / 15685551.2014 .907615$

[3] Kim S. D., Lee S., Heo J., Kim S. Y., Chung I. S.: Soluble polyimides with trifluoromethyl pendent groups. Polymer, 54, 5648-5654 (2013).

DOI: $10.1016 /$ j.polymer.2013.08.057

[4] Dodda J. M., Kováŕík T., Kadlec J., Kullová L.: Preparation, characterization and thermal degradation study of poly(amide imide)s based on tri-component mixture of PMDA/BTDA, diamines and acid chloride. Polymer Degradation and Stability, 98, 2306-2316 (2013). DOI: $10.1016 /$ j.polymdegradstab.2013.08.010

[5] Banihashemi A., Atabaki F.: Synthesis and characterization of new thermally stable polybenzimidazoles and poly(amide-benzimidazole)s. European Polymer Journal, 38, 2119-2124 (2002). DOI: 10.1016/S0014-3057(02)00081-2

[6] Banihashemi A., Akhlaghinia B.: New heat stable polyethers, polyketones and polysulfones. Macromolecular Chemistry and Physics, 200, 2284-2293 (1999). DOI: 10.1002/(SICI)1521-3935(19991001)200:10<2284 :AID-MACP2284>3.0.CO;2-X
[7] Honkhambe P. N., Bhairamadgi N. S., Biyani M. V., Wadgaonkar P. P., Salunkhe M. M.: Synthesis and characterization of new aromatic polyesters containing cardo decahydronaphthalene groups. European Polymer Journal, 46, 709-718 (2010).

DOI: 10.1016/j.eurpolymj.2009.12.028

[8] Liaw D-J., Wang K-L., Huang Y-C., Lee K-R., Lai JY., Ha C-S.: Advanced polyimide materials: Syntheses, physical properties and applications. Progress in Polymer Science, 37, 907-974 (2012).

DOI: $10.1016 /$ j.progpolymsci.2012.02.005

[9] Mathews A. S., Kim I., Ha C-S.: Synthesis, characterization, and properties of fully aliphatic polyimides and their derivatives for microelectronics and optoelectronics applications. Macromolecular Research, 15, 114-128 (2007).

DOI: $10.1007 / \mathrm{BF} 03218762$

[10] Tao L., Yang H., Liu J., Fan L., Yang S.: Synthesis and characterization of highly optical transparent and low dielectric constant fluorinated polyimides. Polymer, 50, 6009-6018 (2009).

DOI: 10.1016/j.polymer.2009.10.022

[11] Zhai L., Yang S., Fan L.: Preparation and characterization of highly transparent and colorless semi-aromatic polyimide films derived from alicyclic dianhydride and aromatic diamines. Polymer, 53, 3529-3539 (2012). DOI: $10.1016 /$ j.polymer.2012.05.047

[12] Chen J-C., Wu J-A., Li S-W., Chou S-C.: Highly phenylated polyimides containing 4,4'-diphenylether moiety. Reactive and Functional Polymers, 78, 23-31 (2014).

DOI: 10.1016/j.reactfunctpolym.2014.02.010

[13] Huang M., Wang L., Li X., Yan S., Yeung K. W., Chu P. $\mathrm{K}$., Xu Z., Yi C.: Design and preparation of novel fluorescent polyimides containing ortho-linked units and pyridine moieties. Designed Monomers and Polymers, 15, 389-404 (2012).

DOI: $10.1080 / 1385772 X .2012 .686691$

[14] Zhang K., Niu H., Wang C., Bai X., Lian Y., Wang W.: Novel aromatic polyimides with pendent triphenylamine units: Synthesis, photophysical, electrochromic properties. Journal of Electroanalytical Chemistry, 682, 101-109 (2012).

DOI: 10.1016/j.jelechem.2012.06.018

[15] Wang C., Chen W., Chen Y., Zhao X., Li J., Ren Q.: New fluorinated poly(ether sulfone imide)s with high thermal stability and low dielectric constant. Materials Chemistry and Physics, 143, 773-778 (2014).

DOI: $10.1016 / \mathrm{j}$. matchemphys.2013.10.012

[16] Liu J., Zhang Q., Xia Q., Dong J., Xu Q.: Synthesis, characterization and properties of polyimides derived from a symmetrical diamine containing bis-benzimidazole rings. Polymer Degradation and Stability, 97, 987-994 (2012).

DOI: 10.1016/j.polymdegradstab.2012.03.010 
[17] Wu J., Yang S., Gao S., Hu A., Liu J., Fan L.: Preparation, morphology and properties of nano-sized $\mathrm{Al}_{2} \mathrm{O}_{3} /$ polyimide hybrid films. European Polymer Journal, 41, 73-81 (2005).

DOI: 10.1016/j.eurpolymj.2004.08.014

[18] Deligöz H., Vatansever S., Öksüzömer F., Koç S. N., Özgümüş S., Gürkaynak M. A.: Synthesis and characterization of sulfonated homo- and co-polyimides based on 2,4 and 2,5-diaminobenzenesulfonic acid for proton exchange membranes. Polymers for Advanced Technologies, 19, 1792-1802 (2008).

DOI: $10.1002 /$ pat.1196

[19] Yang C-P., Yang H-W.: Preparation and characterization of organosoluble copolyimides based on a pair of commercial aromatic dianhydride and one aromatic diamine, 1,4-bis(4-aminophenoxy)-2-tert-butylbenzene, series. Journal of Applied Polymer Science, 75, 87-95 (2000).

DOI: 10.1002/(SICI)1097-4628(20000103)75:1<87:: AID-APP10>3.0.CO;2-R

[20] Yang C-P., Chen R-S.: Preparation and characterization of organosoluble copolyimides based on a pair of commercial aromatic dianhydride and one aromatic diamine, 1,2-bis(4-aminophenoxy)-4-tert-butylbenzene, series. Colloid and Polymer Science, 279, 736 744 (2001).

DOI: $10.1007 / \mathrm{s} 003960000479$

[21] Feng L., Iroh J. O.: Polyimide- $b$-polysiloxane copolymers: Synthesis and properties. Journal of Inorganic and Organometallic Polymers and Materials, 23, 477-488 (2013). DOI: $10.1007 / \mathrm{s} 10904-012-9795-4$

[22] Adhikari R., Dao B., Hodgkin J., Mardel J.: Synthesis, structures and membrane properties of siloxane-imide co-polymers produced by aqueous polymerization. European Polymer Journal, 47, 1328-1337 (2011) DOI: $10.1016 /$ j.eurpolymj.2011.02.018

[23] Ghosh A., Banerjee S.: Synthesis, characterization, and comparison of properties of novel fluorinated poly (imide siloxane) copolymers. Journal of Applied Polymer Science, 107, 1831-1841 (2008).

DOI: $10.1002 / a p p .27241$

[24] Ghosh A., Banerjee S.: Thermal, mechanical, and dielectric properties of novel fluorinated copoly(imide siloxane)s. Journal of Applied Polymer Science, 109, 2329-2340 (2008).

DOI: $10.1002 / a p p .28298$

[25] Ghosh A., Banerjee S., Häußler L., Voit B.: New fluorinated poly(imide siloxane) random and block copolymers with variation of siloxane loading. Journal of Macromolecular Science Part A: Pure and Applied Chemistry, 47, 671-680 (2010).

DOI: $10.1080 / 10601325.2010 .483364$

[26] Ghosh A., Sen S. K., Dasgupta B., Banerjee S., Voit B.: Synthesis, characterization and gas transport properties of new poly(imide siloxane) copolymers from 4,4'(4,4'-isopropylidenediphenoxy)bis(phthalic anhydride). Journal of Membrane Science, 364, 211-218 (2010). DOI: $\underline{10.1016 / \mathrm{j} . \mathrm{memsci} .2010 .08 .015}$
[27] Kang J. H., Cho K., Park C. E.: Adhesion strength of poly(imide-siloxane) with Alloy 42 lead frame and silicon dioxide. Polymer, 42, 2513-2520 (2001). DOI: 10.1016/S0032-3861(00)00548-6

[28] Othman M. B. H., Ramli M. R., Tyng L. Y., Ahmad Z., Akil H. M.: Dielectric constant and refractive index of poly (siloxane-imide) block copolymer. Materials and Design, 32, 3173-3182 (2011). DOI: $10.1016 /$ j.matdes.2011.02.048

[29] Ku C-K., Ho C-H., Chen T-S., Lee Y-D.: Synthesis and characterization of pyridine-containing poly(imidesiloxane)s and their adhesion to copper foil. Journal of Applied Polymer Science, 104, 2561-2568 (2007). DOI: 10.1002/app.24719

[30] Perrin D. D., Armarego W. L. F., Perrin D. R.: Purification of laboratory chemicals. Pergamon, Oxford (1988).

[31] Sheldrick G. M.: Crystal structure refinement with SHELXL. Acta Crystallographica Section C, 71, 3-8, 2015. DOI: $10.1107 / \mathrm{S} 2053229614024218$

[32] Simionescu M., Marcu M., Cazacu M.: New poly(amideimide) siloxane copolymers by polycondensation. European Polymer Journal, 39, 777-784 (2003). DOI: 10.1016/S0014-3057(02)00290-2

[33] Hamciuc E., Hamciuc C., Cazacu M., Ignat M., Zarnescu G.: Polyimide-polydimethylsiloxane copolymers containing nitrile groups. European Polymer Journal, 45, 182-190 (2009).

DOI: $10.1016 /$ j.eurpolymj.2008.10.028

[34] Ma T., Zhang S., Li Y., Yang F., Gong C., Zhao J.: Synthesis and characterization of novel polyimides derived from 4-phenyl-2, 6-bis [3-(4-aminophenoxy)-phenyl]pyridine diamine and aromatic dianhydrides. Polymer Degradation and Stability, 95, 1244-1250 (2010). DOI: $10.1016 /$ j.polymdegradstab.2010.03.026

[35] Bu Q., Zhang S., Li H., Li Y., Gong C., Yang F.: Preparation and properties of thermally stable polyimides derived from asymmetric trifluoromethylated aromatic diamines and various dianhydrides. Polymer Degradation and Stability, 96, 1911-1918 (2011). DOI: $10.1016 /$ j.polymdegradstab.2011.07.003

[36] Simionescu M., Marcu M., Cazacu M., Racleș C.: Poly(siloxaneimide)s 2. Polycondensation of some imidic diacid chlorides with aminoalkylsiloxanes. European Polymer Journal, 38, 229-233 (2002). DOI: $10.1016 / \mathrm{S} 0014-3057(01) 00184-7$

[37] Khan M. S. U., Akhter Z., Naz T., Bhatti A. S., Siddiqi H. M., Siddiq M., Khan A.: Study on the preparation and properties of novel block copolymeric materials based on structurally modified organometallic as well as organic polyamides and polydimethylsiloxane. Polymer International, 62, 319-334 (2013).

DOI: $10.1002 /$ pi.4305 